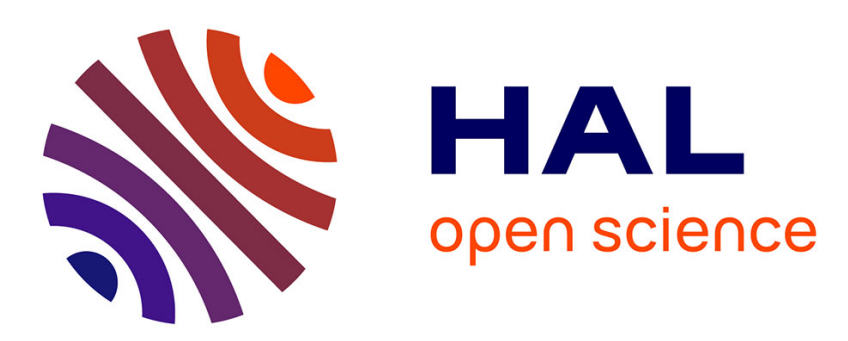

\title{
Magnetization measurements of nearly ferromagnetic compounds TiBe 2-xMx (M = Cu, Ag, Au, Fe) in low and high fields
}

F. Acker, R. Huguenin, J.L. Smith, C.Y. Huang

\section{- To cite this version:}

F. Acker, R. Huguenin, J.L. Smith, C.Y. Huang. Magnetization measurements of nearly ferromagnetic compounds TiBe 2-xMx $(\mathrm{M}=\mathrm{Cu}, \mathrm{Ag}, \mathrm{Au}, \mathrm{Fe})$ in low and high fields. Journal de Physique Lettres, 1982, 43 (6), pp.205-209. 10.1051/jphyslet:01982004306020500 . jpa-00232032

\section{HAL Id: jpa-00232032 https://hal.science/jpa-00232032}

Submitted on 1 Jan 1982

HAL is a multi-disciplinary open access archive for the deposit and dissemination of scientific research documents, whether they are published or not. The documents may come from teaching and research institutions in France or abroad, or from public or private research centers.
L'archive ouverte pluridisciplinaire HAL, est destinée au dépôt et à la diffusion de documents scientifiques de niveau recherche, publiés ou non, émanant des établissements d'enseignement et de recherche français ou étrangers, des laboratoires publics ou privés. 
Classification

Physics Abstracts

$75.30 \mathrm{C}$

\title{
Magnetization measurements of nearly ferromagnetic compounds $\mathrm{TiBe}_{2-x} \mathrm{M}_{x}(\mathrm{M}=\mathrm{Cu}, \mathrm{Ag}, \mathrm{Au}, \mathrm{Fe})$ in low and high fields
}

\author{
F. Acker, R. Huguenin \\ Institut de Physique Expérimentale, Université de Lausanne, \\ 1015 Lausanne, Switzerland
}

\author{
J. L. Smith and C. Y. Huang \\ Los Alamos National Laboratory, Los Alamos, New Mexico 87545, U.S.A.
}

(Reçu le 21 décembre 1981, accepté le ler février 1982)

\begin{abstract}
Résumé. - Nous observons une croissance monotone de la susceptibilité des composés $\mathrm{TiBe}_{2-x} \mathrm{Cu}_{x}$ avec la concentration du cuivre. Des mesures de l'aimantation à $1,24 \mathrm{~K}$ et 4,17 $\mathrm{K}$ dans des champs atteignant $213 \mathrm{kOe}$ sont analysées à l'aide du formalisme de Landau des transitions de phase. La concentration critique pour le ferromagnétisme, $x_{\mathrm{c}}$, est de l'ordre de 0,2 . L'introduction des solutés $\mathrm{Ag}$ et $\mathrm{Au}$ diminue la susceptibilité de $\mathrm{TiBe}_{2}$ (résultats préliminaires). Dans les composés $\mathrm{TiBe}_{2-x} \mathrm{Fe}_{x}$ le moment magnétique du fer paraît être inférieur à $0,01 \mu_{\mathrm{B}}$.
\end{abstract}

\begin{abstract}
It is shown that the substitution of minute amounts of $\mathrm{Cu}$ for $\mathrm{Be}$ in $\mathrm{TiBe}_{2}$ causes the susceptibility to increase monotonically. Magnetization data for $\mathrm{TiBe}_{2-x} \mathrm{Cu}_{x}$ at $1.24 \mathrm{~K}$ and $4.17 \mathrm{~K}$ in fields up to $213 \mathrm{kOe}$ are analysed in the Landau model of phase transitions. The critical concentration for ferromagnetism, $x_{\mathrm{c}}$, is about 0.2 . $\mathrm{Ag}$ and $\mathrm{Au}$ as solutes decrease the susceptibility of $\mathrm{TiBe}_{2}$ (preliminary results). The magnetic moment of $\mathrm{Fe}$ in $\mathrm{TiBe}_{2-x} \mathrm{Fe}_{x}$ is estimated to be smaller than $0.01 \mu_{\mathrm{B}}$
\end{abstract}

The magnetic properties of $\mathrm{TiBe}_{2}$, the susceptibility of which goes through a maximum for both increasing magnetic field and increasing temperature, are not yet fully elucidated [1]. This cubic (C15) compound has been recently described as an antiferromagnet [2, 3], a metamagnet $[4,5]$ and - for the time being the prevailing view - as a strongly exchange enhanced paramagnet $[6,7,8]$.

Derived compounds such as $\mathrm{TiBe}_{2-x} \mathrm{M}_{x}$ may also show remarkable properties. A striking feature is the occurrence of ferromagnetism in $\mathrm{TiBe}_{2-x} \mathrm{Cu}_{x}[9,8,6,10,11]$ for $x \sim 0.16$ [8]. No detailed theoretical or experimental study of the changes in the electronic structure of $\mathrm{TiBe}_{2}$ caused by the introduction of $\mathrm{Cu}$ is available yet. Moreover, the situation is obscured by the discrepancy between our magnetization data $[8,1]$ and those of Monod et al. and Felner et al. [6, 11]. We found in [8] that the low field, low-temperature susceptibility, $\chi(0,0)$, of $\mathrm{TiBe}_{2-x} \mathrm{Cu}_{x}$ compounds increases regularly from $x=0$ through $x=0.012,0.05,0.10$, etc... By contrast the susceptibility reported in [6] and [11] for $x=0.02$ and $x=0.03$ is roughly two times smaller than that of $\mathrm{TiBe}_{2}$. Thus Felner et al. recently reaffirmed that the substitution of minute amounts 
of $\mathrm{Cu}$ for $\mathrm{Be}$ in $\mathrm{TiBe}_{2}$ causes the susceptibility to go through a minimum [11]. In an attempt to definitely clarify that point we measured the susceptibility of three more $\mathrm{TiBe}_{2-x} \mathrm{Cu}_{x}$ samples $(x=0.008,0.027$ and 0.038$)$. The results are presented here together with partly published data [8] for the same system. Preliminary susceptibility measurements for $\operatorname{TiBe}_{2-x} \mathbf{M}_{x}(\mathrm{M}=\mathrm{Ag}, \mathrm{Au}, \mathrm{Fe})$ are also included.

Experiments were carried out in the liquid ${ }^{4} \mathrm{He}$ temperature range with a precision moving sample magnetometer, in fields $(H)$ up to $68 \mathrm{kOe}$, and with an apparatus of the same type [12], at the National Magnet Laboratory, where fields up to $213 \mathrm{kOe}$ were used. The preparation of the $\mathrm{TiBe}_{2-x} \mathrm{Cu}_{x}$ compounds (arc-melted and annealed) has been described earlier [9, 10]. The samples with solutes other than $\mathrm{Cu}$ were only arc-melted, except for $\mathrm{TiBe}_{1.9} \mathrm{Ag}_{0.1}$ which was also annealed.

Figure 1 shows the variation with concentration of the susceptibility of $\mathrm{TiBe}_{2-x} \mathrm{Cu}_{x}$ at $4.17 \mathrm{~K}$. We plotted the Landau parameters $A \equiv \chi^{-1}(H \rightarrow 0)$ and $B$, obtained from Arrott plots of the magnetization $\left(M^{2}\right.$ vs. $\left.H / M\right)$. As shown in [1] and first suggested in [6], such plots are straight lines for $\mathrm{TiBe}_{2}$ at helium temperatures, up to magnetic fields of about $40 \mathrm{kOe}$. The magnetization $M(T, x, H)$ of $\mathrm{TiBe}_{2-x} \mathrm{Cu}_{x}$ can also be described by the relation $H / M=A(T, x)+B(x) M^{2}$.

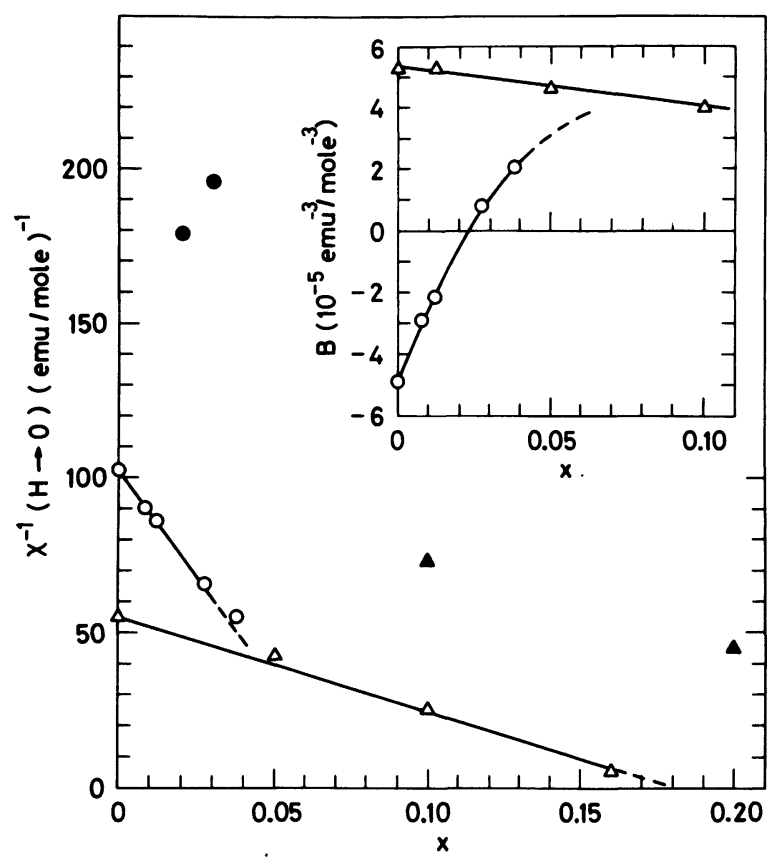

Fig. 1. - Inverse magnetic susceptibility of $\mathrm{TiBe}_{2-x} \mathrm{Cu}_{x}$ compounds, at $4.2 \mathrm{~K}$, as a function of $\mathrm{Cu}$ concentration. Present results are shown by open symbols. Closed symbols are from references [6] and [11]. The data were obtained from Arrott plots $\left(M^{2} v\right.$ s. $\left.H / M\right)$. Circles correspond to measurements for $0<H<40 \mathrm{kOe}$ and triangles to the highest field range (see text). Insert, variation with concentration of the Landau parameter $B$.

It is clear from the results for the most dilute samples $(x<0.03)$ that the susceptibility increases regularly with $\mathrm{Cu}$ concentration (Fig. 1, open circles). The initial variation of $\chi^{-1}$ is given by $\chi^{-1}(x)=\chi^{-1}(0)-\alpha x$, with $\alpha=1330(\mathrm{emu} / \mathrm{mole})^{-1}$. Also shown, for comparison, are the quite different susceptibility values found by Monod et al. [6] and Felner et al. [11]. The Landau parameter $B$ (i.e. the inverse slope of the Arrott plots) does also vary smoothly with $x$ (see insert). This initially negative coefficient changes its sign at $x \simeq 0.023$. 
The results shown in figure 1 were extracted from figure 2 which shows more explicitly the variation of the magnetization with field, concentration of various solutes and, marginally, temperature. The data points for $\mathrm{TiBe}_{2-x} \mathrm{Cu}_{x}$ with $x=0.008,0.027$ and 0.038 were omitted in figure 2 , for clarity.

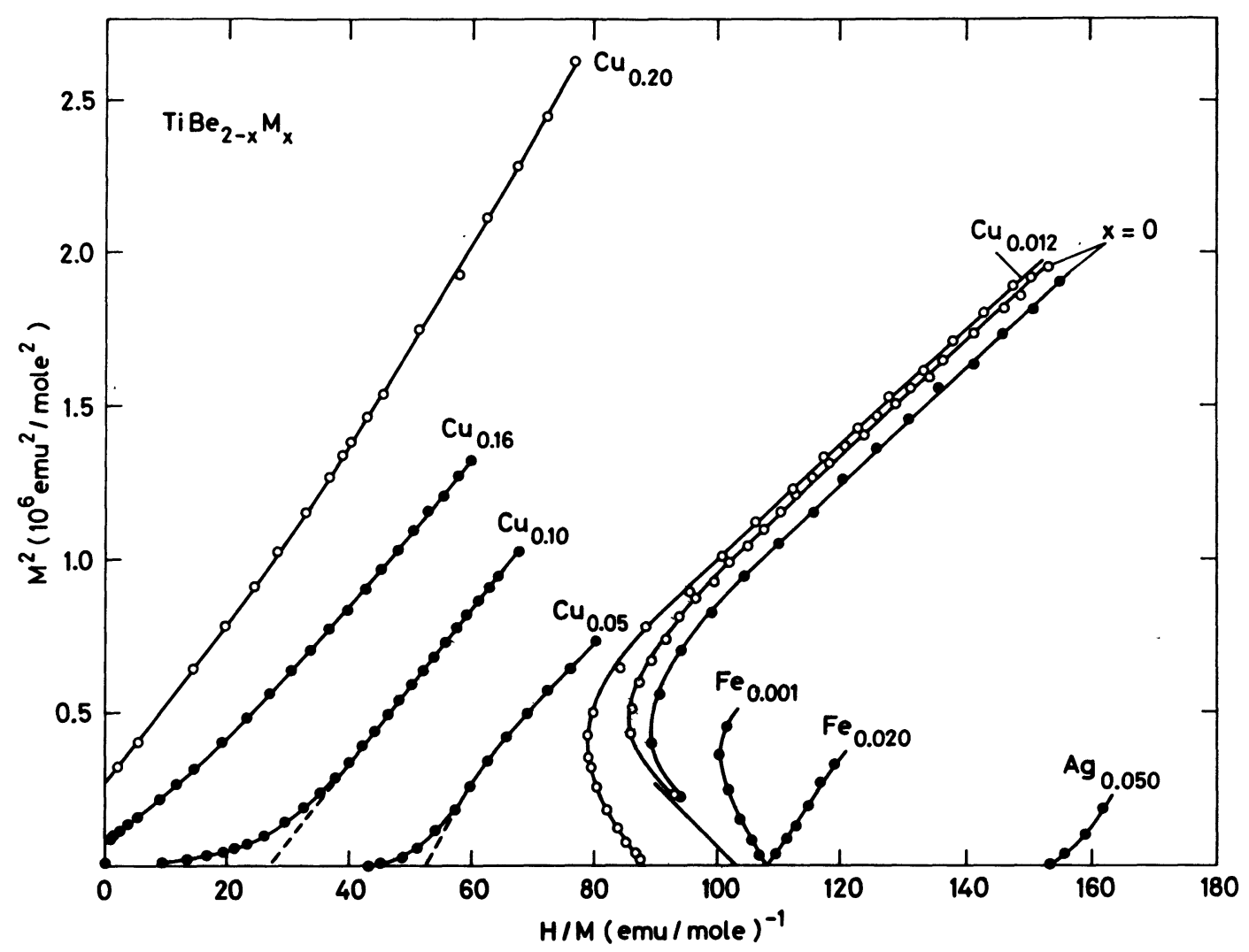

Fig. 2. - Arrott plots $\left(M^{2}\right.$ vs. $\left.H / M\right)$ of the magnetization of $\mathrm{TiBe}_{2-x} \mathrm{M}_{x}(\mathrm{M}=\mathrm{Cu}, \mathrm{Ag}, \mathrm{Fe})$ compounds. Open symbols, $T=1.24 \mathrm{~K}$. Closed symbols, $T=4.17 \mathrm{~K}$. Data for $\mathrm{TiBe}_{2}$ and $\mathrm{TiBe}_{1.988} \mathrm{Cu}_{0.012}$ extend up to $213 \mathrm{kOe}$. The straight segment (near $H / M=100$ ) represents our detailed measurements [1] for $\mathrm{TiBe}_{2}$ at $1.45 \mathrm{~K}$. All samples were annealed, except those containing $\mathrm{Ag}$ and $\mathrm{Fe}$.

It is seen in figure 2 that the Arrott plots for $\mathrm{TiBe}_{2}$ at $1.24 \mathrm{~K}$ and $4.17 \mathrm{~K}$ " turn around » in moderate fields (45 $₹ H \gtrless 55 \mathrm{kOe}$, see [1] for details) and become nearly rectilinear again at very high fields $(100<H<213 \mathrm{kOe})$. In that field range $B$ is positive and the corresponding values of $A$ are about two times smaller than the inverse susceptibility in zero field.

The values of $\chi^{-1}$ and $B$ obtained from the data in the highest field range are shown in figure 1 by triangles. For $\mathrm{TiBe}_{2-x} \mathrm{Cu}_{x}$ with $x=0.05,0.10$ and 0.16 we determined $\chi^{-1}$ and $B$ in the range $40 \leqslant H \leqslant 68 \mathrm{kOe}$. In spite of this minor inconsistency, a rather smooth variation of the parameters with concentration is found.

From figure 1 it appears that the magnetization of $\mathrm{TiBe}_{2-x} \mathrm{Cu}_{x}$ with $x>0.05$ can be described in the whole range of field with a single pair of values for the parameters $A(T, x)$ and $B(x)$ whereas this is not possible for the compounds with a smaller $\mathrm{Cu}$ content. Remarkably, only the Landau parameters determined from high field data vary in a simple way when the $\mathrm{Cu}$ concentration increases from zero, up to the critical concentration for ferromagnetism, $x_{c} \simeq 0.2$ (Fig. 1, open triangles). 
Obviously, magnetic inhomogeneity in the more concentrated samples gives rise to low field tails in the Arrott plots. It is important to notice that such a tail is not observed in the plots for $x<0.02$ and becomes barely visible for $x=0.027\left(\Delta \chi^{-1} / \chi^{-1} \simeq 2 \%\right.$; compare with the larger and larger tails for $x=0.05$ and 0.10 , in the same range of field, $2<H<20 \mathrm{kOe}$ ). This indicates that the increase in $\chi$ at low $\mathrm{Cu}$ concentration is intrinsic and is not due to the presence of small ferromagnetic regions.

It appears that the two concentrated $\mathrm{TiBe}_{2-x} \mathrm{Cu}_{x}$ samples $(x=0.1$ and $x=0.2)$ measured by Monod et al. [6] at low temperatures are very inhomogeneous. The Arrott plots, for both samples, have a pronounced low field tail (only $M$ vs. $H$ was shown in reference [6]). In high fields, the magnetization of the $\mathrm{TiBe}_{1.9} \mathrm{Cu}_{0.1}$ sample lies below our curve for $\mathrm{TiBe}_{2}$ and the latter isotherm practically merges with the data for the $\mathrm{TiBe}_{1.8} \mathrm{Cu}_{0.2}$ specimen. Hence, for $x=0.2$, the extrapolated $\chi^{-1}$ at $4.2 \mathrm{~K}$, which should be nearly zero, is as large as $45(\mathrm{emu} / \mathrm{mole})^{-1}$ (Fig. 1 , closed triangle).

Some more information may be extracted from our data in figure 2.

The high field magnetization curve for $\mathrm{TiBe}_{1.988} \mathrm{Cu}_{0.012}$ at $1.24 \mathrm{~K}$ does not merge with that for $\mathrm{TiBe}_{2}$ at the same temperature. The small relative shift of the Arrott plot for $x=0.012$ toward the left corresponds to a critical concentration for ferromagnetism $x_{\mathrm{c}}=0.24$, of the right order of magnitude $\left({ }^{1}\right)$. This is an additional indication of the quality (homogeneity, nominal concentration) of the samples used $\left({ }^{2}\right)$.

Detailed high field magnetization measurements of $\mathrm{TiBe}_{2}$ at temperatures up to $20-30 \mathrm{~K}$ have not yet been published. The two isotherms of figure 2, at $1.24 \mathrm{~K}$ and $4.17 \mathrm{~K}$, show that the temperature variation of $M$ is strongly field dependent (see Ref. [1] for detailed low field data). In zero field $\chi$ would increase by $0.8 \%$ between $1.24 \mathrm{~K}$ and $4.17 \mathrm{~K}$ (following initially a $T^{2}$ law [1]) while the susceptibility determined by extrapolating the straight high field part of the Arrott plot to $M^{2}=0$, decreases by $10 \%$ in the same temperature interval. For $H \cong 25 \mathrm{kOe}, \chi$ should remain nearly constant between $0 \mathrm{~K}$ and $10 \mathrm{~K}$ [1]. It would be of interest to determine above which temperature $\chi(H)$ no longer goes through a maximum and to measure the high field values of $B$ at high temperatures, also in $\mathrm{TiBe}_{2-x} \mathrm{Cu}_{x}$ compounds.

Some of our preliminary data on $\mathrm{TiBe}_{2-x} \mathrm{M}_{x}(\mathrm{M}=\mathrm{Ag}, \mathrm{Au}, \mathrm{Fe})$ are shown in figure 2 . Thinking in terms of electron concentration, one might expect $\mathrm{Ag}$ and $\mathrm{Au}$ to have qualitatively the same effect as $\mathrm{Cu}$ on the magnetic properties of $\mathrm{TiBe}_{2}$. This is not found in the present experiments. At $4.17 \mathrm{~K}$ the susceptibility of $\mathrm{TiBe}_{1.95} \mathrm{Ag}_{0.05}$ is only $67 \%$ of the value for $\mathrm{TiBe}_{2}$. This ratio is $56 \%$ for $\mathrm{TiBe}_{1.95} \mathrm{Au}_{0.05}$. However these two samples were just arc-melted. For an annealed $\mathrm{TiBe}_{1.9} \mathrm{Ag}_{0.1}$ sample the ratio reaches $86 \%$ and the parameter $B \cong-0.6 \times 10^{-5}(\mathrm{emu} / \mathrm{mole})^{-3}$ is still slightly negative. Since $\mathrm{Ag}$ and $\mathrm{Au}$ have a significantly larger atomic radius than $\mathrm{Cu}$, it is likely that these elements cannot substitute $\mathrm{Be}$ in $\mathrm{TiBe}_{2}$. Anyway, it seems that we failed in introducing them in the compound, as Felner et al. apparently failed in introducing $\mathrm{Cu}$.

As to the $\mathrm{TiBe}_{2-x} \mathrm{Fe}_{x}$ compounds, our susceptibility results are consistent with those of reference [11]. We find that a Fe concentration of 0.02 (arc-melted sample) decreases the susceptibility by about $4 \%$, which is small. On the other hand, this amount of $\mathrm{Fe}$ changes the parameter $B$ from $-5 \times 10^{-5}$ (in $\mathrm{TiBe}_{2}$ ) to $+3 \times 10^{-5}(\mathrm{emu} / \mathrm{mole})^{-3}$ (see Fig. 2). An even larger increase in $B$, per unit concentration, is observed for $x=0.001$. For that sample, $B \simeq-3 \times 10^{-5}$ and the zero field susceptibility is nearly the same as in $\mathrm{TiBe}_{1.98} \mathrm{Fe}_{0.02}$ (within $1 \%$ ). Hence the initial value of $\mathrm{d} B / \mathrm{d} x$ is about 5 times larger for $\mathrm{TiBe}_{2-x} \mathrm{Fe}_{x}$ than for $\mathrm{TiBe}_{2-x} \mathrm{Cu}_{x}$ (with the same sign). The susceptibility $(1 / A)$ seems to remain practically unaffected by $\mathrm{Fe}$ impurities but increases rapidly with $\mathrm{Cu}$ concentration. In band theory, the Landau parameters $A$ and $B$ can be expressed

( $\left.{ }^{1}\right)$ It is clear from figure 2 that $x_{\mathrm{c}}$ depends on the range of field used. For $H>100 \mathrm{kOe}, x_{\mathrm{c}}$ would lie above $x=0.22$.

( $\left.{ }^{2}\right) \mathrm{TiBe}_{1.95} \mathrm{Cu}_{0.05}$ is an exception. By comparison with the latest samples made $(x=0.027,0.038)$ we estimate that its magnetization should be larger by a factor 1.08 . 
in terms of the density, $N\left(E_{\mathrm{F}}\right)$, of the electronic states at the Fermi level and its derivatives with respect to energy. From our results we may infer that the introduction of Fe has a strong effect on the fine structure in the density of states, on which $B$ depends, but does not change much $N\left(E_{\mathrm{F}}\right)$.

One more clear cut result is that $\mathrm{Fe}$ bears no giant moment in $\mathrm{TiBe}_{2}-$ in fact no moment at all. From the absence, within experimental error, of a tail in the low field Arrott plot for $\mathrm{TiBe}_{1.98} \mathrm{Fe}_{0.02}$ we calculated that the magnetic moment per Fe atom is smaller than $10^{-2} \mu_{\mathrm{B}}$. In that respect $\mathrm{TiBe}_{2}$ strongly differs from $\mathrm{Pd}$, as noticed in [11].

In conclusion, the present experimental results clearly show that the substitution of $\mathrm{Cu}$ for $\mathrm{Be}$ in $\mathrm{TiBe}_{2}$ continuously increases the susceptibility. The complicated way the Landau parameters $A$ and $B$ vary with impurity concentration, magnetic field and temperature (also pressure, see Ref. [13]) still calls for further investigations and interpretations.

Acknowledgments. - The financial support of the Swiss National Science Foundation is gratefully acknowledged. The work at Los Alamos was performed under the auspices of the Department of Energy. Part of this work was performed while the authors were Guest Scientists at the Francis Bitter National Magnet Laboratory, which is supported at M.I.T. by the National Science Foundation.

We enjoyed interesting discussions with M. T. Béal-Monod and we thank D. Shaltiel, I. Felner and I. Novik for communicating their data prior to publication.

\section{References}

[1] Acker, F., Huguenin, R., Pelizzone, M. and Smith, J. L., Phys. Rev. 24B (1981) 5404.

[2] Matthias, B. T., Giorgi, A. L., Struebing, V. O. and Smith, J. L., J. Physique Lett. 39 (1978) L-441.

[3] EnZ, C. P., Stewart, G. R., Solid State Commun. 35 (1980) 951.

[4] Wohlfarth, E. P., J. Physique Lett. 41 (1980) L-563 ; Comments Solid State Phys. 10 (1981) 39.

[5] Jarlborg, T. and Freeman, A. J., Phys. Rev. B 23 (1981) 3577.

Van Deursen, A. P. J., Van Ruitenbeek, J. M., Verhoef, W. A., de Vroomen, A. R., Smith, J. L., De Groot, R. A., Koelling, D. D. and Mueller, F. M., preprint.

[6] Monod, P., Felner, I., Chouteau, G. and Shaltiel, D., J. Physique Lett. 41 (1980) L-511.

[7] Shaltiel, D., Monod, P. and Felner, I., J. Physique Lett. 41 (1980) L-567.

[8] ACKer, F., Fisk, Z., Smith, J. L. and Huang, C. Y., J. Magn. Magn. Mater. 22 (1981) 250.

[9] Giorgi, A. L., Matthias, B. T., Stewart, G. R., Acker, F. and Smith, J. L., Solid State Commun. 32 (1979) 455.

[10] SMith, J. L., Physica 107B (1981) 251.

[11] Felner, I., Nowik, I. and Shaltiel, D., Solid State Commun. 40 (1981) 1073.

[12] Foner, S. and MCNifF Jr., E. J., Rev. Sci. Instrum. 39 (1968) 171.

[13] SCHILling, J. S., to be published in The proceedings of the International Symposium on the Physics of Solids under High Pressure, J. S. Schilling and R. N. Shelton, editors (North-Holland, Amsterdam) 1981. 